\title{
Production and characterisation of non-alcoholic beer using special yeast
}

\author{
Peter Vaštík ${ }^{1}$, Daniela Šmogrovičová ${ }^{1}$, Valentína Kafková ${ }^{1}$, Pavol Sulo², Katarína Furdíková ${ }^{1}$, Ivan Špánik ${ }^{1}$ \\ Slovak University of Technology in Bratislava, \\ Faculty of Chemical and Food Technology, Bratislava, Slovakia \\ 2 Comenius University in Bratislava, Faculty of Natural Sciences, \\ Bratislava, Slovakia \\ *corresponding author: daniela.smogrovicova@stuba.sk
}

\begin{abstract}
Non-Saccharomyces yeast strains Saccharomycodes ludwigii, Schizosaccharomyces pombe, Lachancea fermentati and Pichia angusta together with a hybrid yeast strain cross-bred between genetically modified Saccharomyces cerevisiae W303-1A G418 ${ }^{R}$ and Saccharomyces eubayanus as well as the parent yeasts of the hybrid were studied for potential use for non-alcoholic beer production. The hybrid yeast, its Saccharomyces cerevisiae W303-1A G418 ${ }^{\mathrm{R}}$ parent and Saccharomycodes ludwigii were not able to metabolise maltose during Durham tube tests. Schizosaccharomyces pombe, Lachancea fermentati and Pichia angusta metabolised maltose, however, showed limited ethanol production. Parameters, volatile and non-volatile organic compounds of beers produced by the studied yeast were analysed and compared to a beer produced by bottom fermented brewer's yeast Saccharomyces pastorianus.
\end{abstract}

Keywords: low-alcoholic beer, non-alcoholic beer, non-Saccharomyces yeast, hybrid yeast

\section{Introduction}

Over the last years, the consumption of alcohol-free beer has been rising significantly due to the fact that it represents an alternative to standard soft drinks (Kyselová and Brányik, 2015). Consumer interest in health increases and no alcohol policies for drivers and pregnant women are advocated (De Francesco et al., 2018). However, most of the available non-alcoholic beers present a poor flavour profile that is not well accepted (Catarino and Mendes, 2011). The European Union has no law that refers to "low-alcohol" and "alcohol free" beers, but each country has its own legislation (Montanari et al., 2009). Beers with reduced alcohol content are often classified as "low-alcohol" beers containing $1.2 \% \mathrm{v} / \mathrm{v}$ of ethanol, and "non-alcohol" or "alcohol-free" beers containing $0.5 \% \mathrm{v} / \mathrm{v}$ of ethanol (Varela and Varela, 2019). Two main methods can be used to produce these beers. One of them, also called physical, is based on removing alcohol from the alcoholic beer produced by classical technology. This method requires considerable investments into the special equipment for alcohol removal, and the final beer is characterised by poor sensory qualities caused by losing higher alcohols and esters, which must be refilled later (Brányik et al., 2012). The aim of the other method, often referred to as biological, is to reduce alcohol production during fermentation process (Ivanov et al., 2016). Biological methods include using wort with a lower content of simple sugars, early ending of fermentation, lower temperature of fermentation or lower metabolism activity caused by immobilization of the yeasts (Kochláňová et al., 2016b). Non-Saccharomyces yeasts are known for their important contribution to the flavour profile of fermented foods and beverages and have therefore been investigated for their targeted application in bioflavouring and, not least, non/low-alcoholic brewing (Bellut et al., 2019). Several non-Saccharomyces species have been tested for the production of low-alcohol and alcohol-free beers.

The rationale behind this study was to use yeast species that are unable to utilise maltose and/or maltotriose, the main sugars present in wort (Varela and Varela, 2019). It is not necessary to stop fermentation by cooling or yeast 
separation, since fermentation will naturally come to a halt by depletion of fermentable sugars. Saccharomycodes ludwigii can produce alcohol-free beers with rich flavour profiles owing to its aroma production and low performance in fermenting maltose and maltotriose from wort (Michel et al., 2016). In comparison to brewer's yeast some strains of $S$. ludwigii produce higher amounts of esters, higher alcohols and negligible concentrations of diacetyl and other undesired compounds (Kochláňová et al., 2016b). Schizosaccharomyces pombe is fission yeast with a very slow growth rate, a long lag phase and a high vitamin requirement. In addition to glucose, this yeast is able to use glycerol, sucrose, raffinose and maltose as carbon sources. It can also survive very low $\mathrm{pH}$ environments and wide range of temperatures (Loira et al., 2018). Sch. pombe is associated with a high fermentative power similar to $S$. cerevisiae with the production of ethanol up to $15 \% \mathrm{v} / \mathrm{v}$ (Benito et al., 2019). Together with lactic acid and acetic acid bacteria Sch. pombe is also part of microbiological consortium in Kombucha production (Villarreal-Soto et al., 2018).

Members of Lachancea genus, L. thermotolerans and L. fermentati have been associated with grape must and wine fermentation processes in several wine producing countries (Porter et al., 2019). Domizio et al. (2016) proposed $L$. thermotolerans to be a good choice for the production of sour beers in a single fermentation without the need of lactic acid bacteria. There has been a very limited research into $L$. fermentati in connection with a production of volatile compounds. Analyses of the common compounds suggest a strain differentiation regarding the production of higher alcohols, isoamyl alcohol and propanol (Porter et al., 2019). Bellut et al. (2020) studied different strains of L. fermentati isolated from kombucha in a low-alcoholic beer production with the focus on the production of lactic acid at the expense of an ethanol. They prepared low-alcoholic beer with a balanced profile of sweetness and acidity, but due to a stopped fermentation, high diacetyl levels were present.
Hansenula polymorpha (syn. Pichia angusta) is able to ferment glucose, but not galactose, sucrose, maltose or raffinose and is recognized for its enzyme alcohol oxidase, which can oxidise not only methanol, but short chained alcohols as well (Negrutã et al., 2010). Use of non-Saccharomyces yeasts other than Saccharomycodes ludwigii for the production of alcohol-free beer has not been studied to a great extent. It is a challenge to find such yeasts that are able to produce aromatic compounds which can mask the wort-like off-flavours created by residual wort sugars and aldehydes (Bellut et al., 2018).

The objective of this study was to investigate the application of the selected non-conventional yeasts for the production of non-alcoholic beer. Further we compared profiles of produced beers and beer prepared by standard bottom fermenting brewer's yeast $S$. pastorianus W96.

\section{Materials and methods}

\subsection{Microorganisms}

Yeasts (Table 1) were gained from yeast collections and the control strain of Saccharomyces pastorianus W96 was obtained from a local brewery (its origin is in the Collection of Brewing Yeast of the Research Institute of Brewing and Malting, Prague, Czech Republic). The hybrid yeast was prepared at the Faculty of Natural Sciences of the Comenius University in Bratislava, Slovakia. One hybrid parent, an auxotroph haploid of Saccharomyces cerevisiae W303-1A G418, was constructed by a replacement of a wild type $A A C 1$ gene with aac1::kanMX4 allele from the international systematic $S$. cerevisiae gene disruption project (Baker Brachmann et al., 1998). The other hybrid parent was a culture strain of Saccharomyces eubayanus PYCC121. The construction of the hybrid and its use in this work was motivated by the effort to imitate a natural hybridisation event and to reveal the influence of recombination on the inherited features of the offspring.

Table 1 List of yeast strains

\begin{tabular}{|c|c|c|}
\hline Yeasts & Descriptions & Abbreviations \\
\hline Hybrid $(\mathrm{SCP} \times \mathrm{SEP})$ & Hybrid strain mtDNA from Saccharomyces cerevisiae W303-1A G418 ${ }^{R}$ & HYB \\
\hline Saccharomyces cerevisiae W303-1A G418 ${ }^{\mathrm{R}}$ & $\begin{array}{c}\text { MATa, ade2-1, trp1-1, leu2-3,112, his3-11,15, ura3-1, can1-100, } \\
\text { aac1::kanMX4, Gal+, psi+, } \rho+\text { parent of the hybrid }\end{array}$ & SCP \\
\hline Saccharomyces eubayanus PYCC121 & Wild strain, parent of the hybrid & SEP \\
\hline Saccharomycodes ludwigii CCY 34-1-2 & & SLU \\
\hline Schizosaccharomyces pombe NRRL Y-12796 & & SPO \\
\hline Lachancea fermentati CBS 4506 & & LFE \\
\hline Pichia angusta CBS 7073 & & PAN \\
\hline Saccharomyces pastorianus W96 & Control bottom-fermenting yeast & W96 \\
\hline
\end{tabular}




\subsection{Carbohydrate fermentation tests}

Tests were performed in accordance with Kurtzman et al. (2011) in glass tubes containing Durham tubes and $2 \% \mathrm{w} / \mathrm{v}$ sugar solution with bromothymol blue as an acid base indicator. Production of $\mathrm{CO}_{2}$ in Durham tubes was evaluated after 7 days of static cultivation at $25^{\circ} \mathrm{C}$.

\subsection{Pre-fermentation and fermentation}

Yeasts were inoculated from Petri dishes into $100 \mathrm{ml}$ Erlenmeyer flasks containing $20 \mathrm{ml}$ of YPD (Yeast Extract-Peptone-Dextrose) pre-fermentation medium. They were cultivated on a rotary shaker for $24 \mathrm{~h}$, at $25^{\circ} \mathrm{C}$ and $180 \mathrm{rpm}$. Wort of the original gravity $10.42^{\circ} \mathrm{P}$ prepared from Pilsen malt (100\%) and Premiant Hops by infusion mashing in $20 \mathrm{l}$ Speidel Braumeister microbrewery served as a fermentation medium. After $24 \mathrm{~h}$ of yeast cultivation, the volume of a pre-fermentation medium corresponding to the pitching rate of $1 \times 10^{6}$ yeast cells $/ \mathrm{ml}$ (cell count for each yeast strain was performed under a microscope with the Bürker chamber) was added into $500 \mathrm{ml}$ flasks containing a fermentation medium to reach $400 \mathrm{ml}$. The primary fermentation was carried out in $500 \mathrm{ml}$ flasks with fermentation seals at $12{ }^{\circ} \mathrm{C}$ for 7 days. After 7 days young beers were poured through filter into $300 \mathrm{ml}$ fermentation flasks and sealed. Beers underwent maturing at $4{ }^{\circ} \mathrm{C}$ for 21 days. Matured beers were then analysed.

\subsection{Analyses of produced beers}

For analyses of beer parameters, $50 \mathrm{ml}$ of beer samples were centrifuged for $10 \mathrm{~min}$ at $3000 \mathrm{rpm}$ and degassed using sonification for $30 \mathrm{~min}$ ). Ethanol concentration, $\mathrm{pH}$, colour, both original and real extracts, and a real degree of fermentation were determined using a DMA 4500M density meter coupled with Alcolyzer Beer ME, Haze QC ME Turbidity Measuring Module and $\mathrm{pH}$ ME Beverage Measuring Module (Anton Paar, GmbH, Graz, Austria). Samples for the analysis of organic compounds (OC) were prepared as follows: $6 \mathrm{ml}$ of cool beer together with $0.5 \mathrm{~g} \mathrm{NaCl}$ (Merck, Darmstadt, Germany) and $20 \mu \mathrm{l}$ of ethanol solution of $1.60 \mathrm{mg} / \mathrm{l}$ benzophenone (internal standard) were placed into a $20 \mathrm{ml}$ glass headspace vial and sealed with metallic hole cup and PTFE/Silicone septa. The analysis of OC in beer samples by HS-SPME-GC $\times$ GC-TOF-MS (headspace-solid phase microextraction comprehensive gas chromatography connected to high resolution time of flight mass spectrometry) was performed in accordance with methods used by Furdíková et al. (2020). Processing of the obtained data was performed using LECO Chroma TOF-HRT 1.90.60 Software and the US National Institute of Standards and Technology (NIST 2014) mass spectra library. The identification of OC was confirmed by accurate mass measurements and comparison of the measured retention index (RI) with the RI obtained by an injection of authentic standards or with a reference value obtained from NIST WebBook (2020). Volatile organic compounds were considered as identified if the difference between the experimental and reference RI was less than 20 units. Relative concentrations of OC were calculated by the ratio of each individual peak area to the area of internal standard and converted to concentration equivalents based on the internal mass added. The following authentic standards obtained from Merck had the purity of $\geq 99.5 \%$ and were used to identify OC by GC×GC: ethyl hexanoate, ethyl octanoate, ethyl decanoate, ethyl dodecanoate, ethyl tetradecanoate, ethyl hexadecanoate, 2-phenylethyl acetate, 2-phenyl ethanol, amyl and isoamyl alcohol, 1-octanol, 1-decanol, guaiacol, 4-vinylguaiacol, 3-methylbutanoic, hexanoic, octanoic, decanoic, dodecanoic, tetradecanoic and hexadecanoic acid, 2,3-butanedione, benzeneacetaldehyde, benzaldehyde, furfural, 5-hydroxymethylfurfural and benzophenone.

\section{Results and discussion}

\subsection{Yeast characterisation}

When characterising non-Saccharomyces yeasts for their suitability in alcohol-free beer production, several key attributes should be investigated. The first attribute is the ability to utilize wort saccharides, mainly maltose, which is the most abundant one (about 65\%) in the wort (Briggs et al., 2004) and could be a significant feature of potential non/low-alcoholic brewing yeast candidate (Bellut et al., 2018). Over the years, various tests have been devised to detect the production of carbon dioxide from carbohydrates by fermenting yeast (van der Walt, 1970). An interesting approach was used by Michel et al. (2020) who determined the yeast fermentation ability through the correlation between sugar depletion and formed pressure. However, the Durham tubes test (Kurtzman et al., 2011) have been found to be the most useful for routine purposes. Therefore, this method was used in our study. The hybrid yeast (HYB) - a descendant of Saccharomyces cerevisiae W303-1A G418 (SCP) and Saccharomyces eubayanus PYCC121 (SEP), as well as the parent yeast Saccharomyces cerevisiae W303-1A G418 ${ }^{\mathrm{R}}$ (SCP) were not able to ferment maltose. Similarly and as presumed, Saccharomycodes ludwigii CCY 34-1-2 (SLU) did not utilise maltose (Table 2). 
Table 2 Carbohydrate fermentation tests of tested yeasts

\begin{tabular}{|c|c|c|c|c|}
\hline Yeasts & Glucose & Maltose & Sucrose & Raffinose \\
\hline Hybrid (SCP × SEP) & +++ & - & +++ & +++ \\
\hline Saccharomyces eubayanus PYCC121 & +++ & +++ & +++ & +++ \\
\hline Saccharomyces cerevisiae W303-1A G418R & +++ & - & +++ & - \\
\hline Schizosaccharomyces pombe NRRL Y-12796 & +++ & + & +++ & +++ \\
\hline Lachancea fermentati CBS 4506 & +++ & +++ & +++ & + \\
\hline Pichia angusta CBS 7073 & +++ & +++ & +++ & + \\
\hline Saccharomycodes ludwigii CCY 34-1-2 & +++ & - & +++ & - \\
\hline Saccharomyces pastorianus W96 & +++ & +++ & +++ & +++ \\
\hline
\end{tabular}

\subsection{Beer parameters}

Beers prepared from the eight studied yeasts were tested for their ethanol content, which is the most important parameter of low/non-alcoholic beer. Further also $\mathrm{pH}$ value, colour, real degree of fermentation (RDF) and real extract (RE) - a portion of not fermented extract were examined (Table 3). The term RDF is the most accurate expression of fermentability (Huerta-Zurita et al., 2019) and it is closely related to the ethanol content in the beer. Ethanol level $<0.5 \% \mathrm{v} / \mathrm{v}$ was detected in beers produced by Saccharomyces cerevisiae W303-1A G418 ${ }^{\mathrm{R}}$ (SCP - 0.38\%), Schizosaccharomyces pombe NRRL Y-12796 (SPO - 0.36\%), Pichia angusta CBS 7073 (PAN - 0.14\%) and Saccharomycodes ludwigii CCY 34-1-2 (SLU - 0.46\%). Therefore, these beers can be labelled as non-alcoholic. Saccharomycodes ludwigii yeasts are well known as agents producing low/non-alcoholic beer producers. De Francesco et al. (2015) also used a strain of $S$. ludwigii and obtained beers with ethanol content $<1 \% \mathrm{v} / \mathrm{v}$. Our beers prepared using the hybrid yeast (HYB $-1.02 \%$ of ethanol) and Lachancea fermentati CBS 4506 (LFE - 0.76\%) can be classified as low-alcoholic ones. Control beer fermented by lager yeast $S$. pastorianus W96 contained $4.04 \%$ of ethanol. The highest RE value (PAN - 10.11\% w/w) and the lowest RDF value (PAN - 2.04\%) were detected in the beer prepared with $P$. angusta CBS 7073. As presumed, the lowest RE value (W96
- 3.95\% w/w) and the highest RDF value (W96 - 62.30\%) were detected in the beer prepared with the control yeast S. pastorianus W96. Increased wort colour during brewing process is caused by the temperature-dependent, non-enzymatic colour reactions of the Maillard type (Phiarais et al., 2010). The colour of the wort used in this study contained 20.61 EBC units and decreased during fermentation and beer maturation. The colour of the prepared beers ranged from 10.09 EBC units (fermented with S. pastorianus W96) to $15.19 \mathrm{EBC}$ units (S. cerevisiae W303-1A $\mathrm{G} 418^{\mathrm{R}}$ - SCP). Correlation between ethanol concentration and beer colour was observed: the higher the beer ethanol concentration, the lower the colour of the beer. Also, more acidic beer gives a lower colour value of the beer. This can be related to the acidic environment, which decreases the colour compounds. Other contributors to the colour of beer are oxidized polyphenols; they occur especially when traces of metals such as iron or copper are present (Briggs et al., 2004; Šavel et al., 2008). The $\mathrm{pH}$ value of beer influences its foam as well as its colloidal and microbiological stability (Liguori et al., 2015). According to Phiarais et al. (2010) the wort pH value usually ranges between 5.6-5.9. In our study the wort $\mathrm{pH}$ was 6.00 . The lowest $\mathrm{pH}$ was detected in the beer prepared with $S$. cerevisiae W303-1A $\mathrm{G} 418^{\mathrm{R}}$ (SCP - 4.64) and the highest $\mathrm{pH}$ value was measured in the beer prepared with hybrid yeast (HYB - 5.04).

Table 3 Parameters of wort and beers (Beer abbreviations correspond to yeast ones, see Table 1)

\begin{tabular}{|l|c|c|c|c|c|c|c|c|c|}
\hline \multicolumn{1}{|c|}{ Parameter/Beer } & Wort & HYB & SEP & SCP & SPO & LFE & PAN & SLU & W96 \\
\hline Ethanol (\% v/v) & - & 1.02 & 2.63 & 0.38 & 0.36 & 0.76 & 0.14 & 0.46 & 4.04 \\
\hline Original extract (\% w/w) & 10.42 & - & - & - & - & - & - & - & - \\
\hline Real extract $(\% \mathrm{w} / \mathrm{w})$ & - & 8.76 & 6.40 & 9.80 & 9.80 & 9.18 & 10.11 & 9.65 & 3.95 \\
\hline Real degree of fermentation (\%) & - & 15.45 & 39.60 & 5.74 & 5.52 & 11.55 & 2.04 & 6.90 & 62.30 \\
\hline Colour (EBC) & 20.61 & 12.41 & 10.75 & 15.19 & 12.77 & 14.03 & 13.61 & 13.22 & 10.09 \\
\hline $\mathrm{pH}$ & 6.00 & 5.04 & 4.69 & 4.64 & 4.97 & 4.96 & 4.91 & 4.82 & 4.86 \\
\hline$-=$ not detected & \multicolumn{7}{|l}{} \\
\hline
\end{tabular}




\subsection{Organic compounds}

The presence of volatile and non-volatile organic compounds and their quantities were evaluated (Table 4). Esters are important sensory active substances produced by cultural yeast. Small differences in the concentration of esters can have a big impact on the final taste of beer (Kochláňová et al., 2016a).

Ethyl hexanoate responsible for apple/banana flavour (Viejo et al., 2019) was detected only in beers prepared with hybrid yeast (HYB - $0.082 \mathrm{mg} / \mathrm{l}$ ), hybrid's parent Saccharomyces eubayanus PYCC121 (SEP - $0.160 \mathrm{mg} / \mathrm{l}$ ) and Lachancea fermentati CBS 4506 (LFE - $0.004 \mathrm{mg} / \mathrm{l}$ ). Significantly high concentration of ethyl octanoate with apple/banana flavour (Viejo et al., 2019) was detected in the beer prepared with hybrid yeast (HYB - $1.226 \mathrm{mg} / \mathrm{l}$ ), which was higher than that in control beer prepared with Saccharomyces pastorianus W96 (W96-1.044 mg/l). The use of non-Saccharomyces yeast Torulospora delbrueckii by Canonico et al. (2016) for production of low/non-alcoholic beer resulted in alcoholic beer $(2.66 \% \mathrm{v} / \mathrm{v}$ of ethanol) with levels of ethyl hexanoate $(0.031 \pm 0.013 \mathrm{mg} / \mathrm{l})$ and ethyl octanoate $(0.006 \pm 0.003 \mathrm{mg} / \mathrm{l})$. 2-Phenylethyl acetate with sweet/honey flavour (Kobayashi et al., 2008) usually ranges in beer from $0.05-2.0 \mathrm{mg} / \mathrm{l}$ (Buiatti, 2009) and was detected in all our beers except those prepared with Pichia angusta CBS 7073 (PAN). Low-alcoholic beer prepared with hybrid yeast (HYB) displayed the highest concentration of ethyl caprate $(0.828 \mathrm{mg} / \mathrm{l})$, ethyl laurate $(0.756 \mathrm{mg} / \mathrm{l})$, ethyl myristate $(0.296 \mathrm{mg} / \mathrm{l})$ and ethyl palmitate $(0.230 \mathrm{mg} / \mathrm{l})$.

Higher alcohols act as the precursors of the more flavour-active esters (Anderson et al., 2019). 2-Phenylethanol with roses/sweetish flavour (Kobayashi et al., 2008) is formed during fermentation with phenyl-alanine catabolism (Andrés-Iglesias et al., 2016), however, it was detected in our wort $(0.114 \mathrm{mg} / \mathrm{l})$, as well. Its concentration ranged from $0.211 \mathrm{mg} / \mathrm{l}$ in the non-alcoholic beer prepared with Schizosaccharomyces pombe NRRL Y-12796 (SPO) to $0.706 \mathrm{mg} / \mathrm{l}$ in the low-alcoholic beer prepared with hybrid yeast (HYB). Amyl alcohol with fusel/fruity flavour (The Goodscents Company, 2020) was detected only in beers prepared with hybrid yeast (HYB - $0.008 \mathrm{mg} / \mathrm{l}$ ) and hybrid's parent S. eubayanus PYCC121 (SEP - $0.007 \mathrm{mg} / \mathrm{l}$ ). Isoamyl alcohol with banana/sweetish flavour (Kobayashi et al., 2008) was detected only in the control beer prepared with S. pastorianus W96 (W96 - $0.066 \mathrm{mg} / \mathrm{l}$ ). Senkarcinova et al. (2019) reported that enhanced formation of higher alcohols is caused by increased fermentation temperatures, and also by shorter maturation times which was observed by Landaud et al. (2001). Hence, the primary fermentation temperature $\left(12^{\circ} \mathrm{C}\right)$ and maturation time (21 days) could have a critical impact on the formation of amyl alcohol and isoamyl alcohol in prepared beers. 1-Octanol (citrus/orange flavour) ranges from 10 to $40 \mu \mathrm{g} / \mathrm{l}$ in ales and 1-decanol (waxy/ fatty flavour) from 5 to $20 \mu \mathrm{g} / \mathrm{l}$ (Phiarais et al., 2010). An increased concentration of 1-octanol was detected in the low-alcoholic beer prepared with hybrid yeast (HYB - $0.51 \mathrm{mg} / \mathrm{l}$ ) and 1-decanol in the non-alcoholic beer prepared with Saccharomycodes ludwigii CCY 34-1-2 (SLU $0.54 \mathrm{mg} / \mathrm{l})$. Fatty acids are beneficial for yeast growth at the beginning of fermentation, but when exposed to oxidation, they can cause an unpleasant off-flavour of beer. Infusion mashing can lead to a higher contents of middle-chain fatty acids (Olšovská et al., 2014).

Octanoic and decanoic acids are important contributors to the flavour of many lager beers (Clapperton and Brown, 1978). The concentration of hexanoic $(0.188 \mathrm{mg} / \mathrm{l})$, octanoic $(0.286 \mathrm{mg} / \mathrm{l})$ and decanoic acid $(0.197 \mathrm{mg} / \mathrm{l})$ in the control beer prepared with $S$. pastorianus W96 (W96) were comparable to those in the low-alcoholic beer prepared with hybrid yeast (HYB): hexanoic $(0.119 \mathrm{mg} / \mathrm{l})$, octanoic $(250 \mathrm{mg} / \mathrm{l})$ and decanoic acid $(0.185 \mathrm{mg} / \mathrm{l})$. The concentration of isovaleric acid $(0.33 \mathrm{mg} / \mathrm{l})$ in the non-alcoholic beer prepared with S. ludwigii in the work of Jiang et al. (2017) was compared to that in a commercial non-alcoholic beer $(0.34 \mathrm{mg} / \mathrm{l})$ and a Pilsner type beer $(0.12 \mathrm{mg} / \mathrm{l})$. The concentration of isovaleric acid in the non-alcoholic beer prepared with S. ludwigii CCY 34-1-2 (SLU) was $0.013 \mathrm{mg} / \mathrm{l}$.

A significant concentration of dodecanoic acid, which plays an important role in the disruption of the beer lacing (Briggs et al., 2004), was detected in the low-alcoholic beer prepared with hybrid yeast (HYB - $0.150 \mathrm{mg} / \mathrm{l}$ ). In the beer prepared with control $S$. pastorianus W96 (W96) it was $0.102 \mathrm{mg} / \mathrm{l}$. Concentrations of myristic $(0.019 \mathrm{mg} / \mathrm{l})$ and palmitic acid $(0.015 \mathrm{mg} / \mathrm{l})$ were the highest in the low-alcoholic beer prepared with hybrid yeast (HYB). Diacetyl (2,3-butanedione) and 2.3-pentadione (vicinal diketones) which results from the chemical oxidative decarboxylation of excess $\alpha$-acetolactate leaked from the valine/leucine biosynthetic pathway to the extracellular environment (De Francesco et al., 2015). The flavour threshold of diacetyl, which imparts beer with a butter or toffee-like flavour commonly ranges between $0.1-0.2 \mathrm{mg} / \mathrm{l}$ in lager and 0.1-0.4 mg/l in ales (Krogerus and Gibson, 2013). Diacetyl was detected only in our beer prepared with the control bottom fermenting brewer's yeast of $S$. pastorianus W96 and its level was above the minimum of the flavour threshold range (W96 - 0.118 $\mathrm{mg} / \mathrm{l}$ ). A formation of aldehydes in beer involves different substrates and mechanism and occurs mainly during wort mashing and boiling (Gernat et al., 2019), but it is also affected by the storage temperature and dissolved 
oxygen presence (Soares da Costa et al., 2004). In this study, the concentration of benzeneacetaldehyde (green/ honey odour) ranged from $0.017 \mathrm{mg} / \mathrm{l}$ in the low-alcoholic beer fermented by hybrid yeast (HYB) to $0.058 \mathrm{mg} / \mathrm{l}$ in the non-alcoholic beer prepared with Sch. pombe NRRL Y-12796 (SPO). A significant concentration of benzaldehyde, a Strecker aldehyde of almond/cherry odour, which is formed during the ageing of beer (Riu-Aumatell et al., 2014), was detected in our non-alcoholic beer prepared with Sch. pombe NRRL Y-12796 (SPO - $0.130 \mathrm{mg} / \mathrm{l}$ ). Furfural with threshold $\geq 0.015 \mathrm{mg} / \mathrm{l}$ and 5-hydroxymethylfurfural with threshold $\geq 0.0358 \mathrm{mg} / \mathrm{l}$ (Saison et al., 2009), the most important aldehydes formed during Maillard reactions, which serve as markers for the heat load impact on the mash, wort and beer (Contreras-Calderón et al., 2008; Germat et al., 2019), were not detected in any of our beers.

During boiling or under the influence of some bacteria and wild yeasts, some ferulic acid is decarboxylated to yield 4-vinyl guaiacol with smoky/bacon odour (The Goodscents Company, 2020), which confers an undesirable flavour in most beers (Briggs et al., 2004). Its formation from ferulic acid during yeast metabolism depends on temperature and yeast strain, but also on lagering duration and pasteurization of the beer (McMurrough et al., 1996). The flavour threshold of 4-vinyl guaiacol in beers (lagers, ales and stouts) is $0.2-0.3 \mathrm{mg} / \mathrm{l}$ (Becker and Gerhäuser, 2008) and in this study its concentration did not exceed the maximum for the flavour threshold level. The highest concentration of guaiacol with woody/phenolic flavour (The Goodscents Company, 2020) was detected in our non-alcoholic beer prepared with $S$. ludwigii CCY 34-1-2 (SLU - 0.029 mg/l).

\section{Conclusions}

Non-Saccharomyces yeasts were regarded to be responsible for microbial-related problems during beer production, which resulted in an almost global use of pure yeast cultures. Numerous previous reports described the potential of the so-called non-conventional yeasts which introduce desirable aromas and flavours to beer during fermentation. Thanks to these reports the role of the non-conventional yeast in the production of beers was revised. Our results confirm that some of the non-conventional yeasts which we tested are suitable for production of non/low-alcoholic beer. It was found that even yeast able to ferment maltose can produce low or non-alcoholic beers, because their ethanol production was limited. The submitted paper was primarily intended as a screening study, in which the yeast strains were exam- ined only on a laboratory scale. It is necessary to perform pilot plant scale-ups of the most interesting strains and to assess their sensory and organoleptic quality by a panel of trained testers.

\section{Acknowledgements}

This article was supported by the Scientific Grant Agency of the Ministry of Education, Science, Research and Sport of the Slovak Republic and the Slovak Academy of Sciences VEGA 1/0063/18, by the Slovak Research and Development Agency APVV-15-0333 and with the support of the Ministry of Education, Science, Research and Sport of the Slovak Republic within the Research and Development Operational Programme for the project 'University Science Park of STU Bratislava', ITMS 26240220084.

\section{References}

Anderson, E. H., Santos, C. I., Hildenbrand, L. Z., Schug, A. K. (2019). A review of the analytical methods used for beer ingredient and finished product analysis and quality control. Analytica Chimica Acta, 1085, 1-20. https://doi.org/10.1016/j.aca.2019.07.061

Andrés-Iglesias, C., Blanco, C. A., García-Serna, J., Pando, V., Montero, O. (2016). Volatile Compound Profiling in Commercial Lager Regular Beers and Derived Alcohol-Free Beers After Dealcoholization by Vacuum Distillation. Food Analytical Methods, 9, 3230-3241. https:// doi.org/10.1007/s12161-016-0513-7

Baker Brachmann, C., Davies, A., Cost, J. G., Caputo, E., Li, J., Hieter, P., Boeke, D. J. (1998). Designer Deletion Strains derived from Saccharomyces cerevisiae S288C: a Useful set of Strains and Plasmids for PCR-mediated Gene Disruption and Other Applications. Yeast, 14, 115-132. https://doi.org/10.1002/(SICI)10970061(19980130)14:2<115::AID-YEA204>3.0.CO;2-2

Becker, H., Gerhäuser, C. (2008). Phenolic compounds in beer. In: Beer in Health and Disease Prevention, (ed. Preedy, R. V.), Academic Press. ISBN 978-0-12-373891-2

Bellut, K., Krogerus, K., Arendt, K. E. (2020). Lachancea fermentati Strains Isolated from Kombucha: Fundamental Insights, and Practical Application in Low Alcohol Beer Brewing. Frontiers in Microbiology, 11, 764. https://doi.org/10.3389/fmicb.2020.00764

Bellut, K., Michel, M., Zarnkow, M., Hutzler, M., Jacob, F., Atzler, J. J., Hoehnel, A., Lynch, K. M., Arendt, E. K. (2019). Screening and Application of $\mathrm{Cy}$ berlindnera Yeasts to Produce a Fruity, Non-Alcoholic Beer. Fermentation, 5(4), 103. https://doi.org/10.3390/fermentation5040103

Bellut, K., Michel, M., Zarnkow, M., Hutzler, M., Jacob, F., De Schutter, P. D., Daenen, L., Lynch, M. K., Zannini, E., Arendt, K. E. (2018). Application of Non-Saccharomyces Yeasts Isolated from Kombucha in the Production of Alcohol-Free Beer. Fermentation, 4(3), 66. https://doi. org/10.3390/fermentation4030066

Benito, Á., Calderón, F., Benito, B. (2019). Schizosaccharomyces pombe and Lachancea thermotolerans: Joint Use as an Alternative to the Traditional Fermentations by Saccharomyces cerevisiae and Oenococcus oeni in Oenology. In: Alcoholic Beverages (eds. Grumezescu, A. G., Holban, A. M.), Elsevier Inc, 387-417. https://doi.org/10.1016/ B978-0-12-815269-0.00012-X 
$\stackrel{\leftrightarrow}{\xi}$

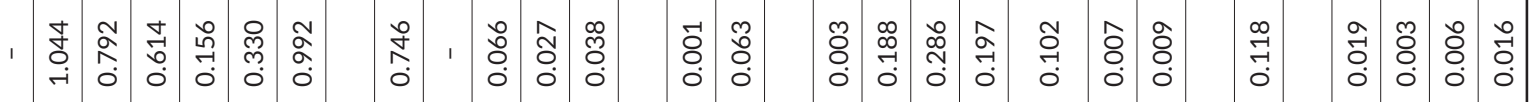

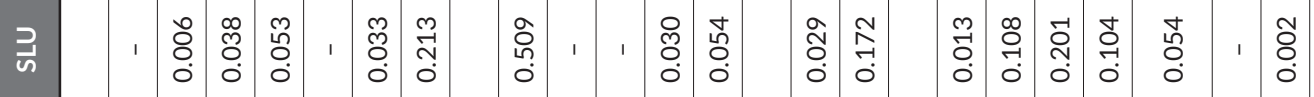

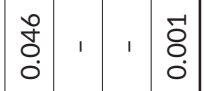

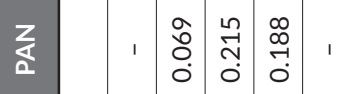

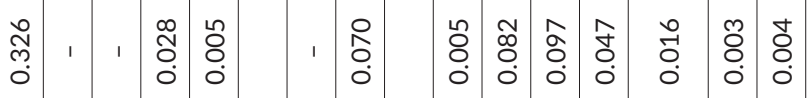

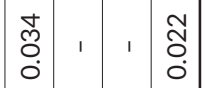

岃

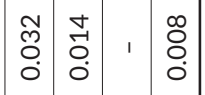

$\stackrel{\circ}{\circ}$

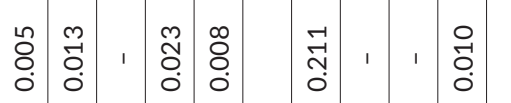

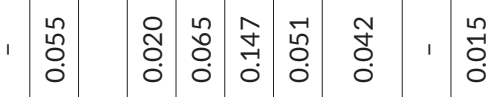

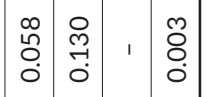

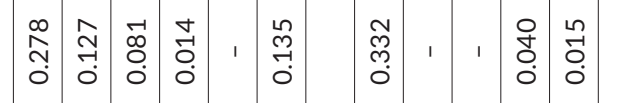

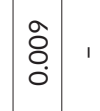

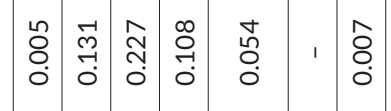

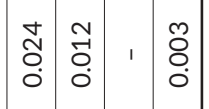

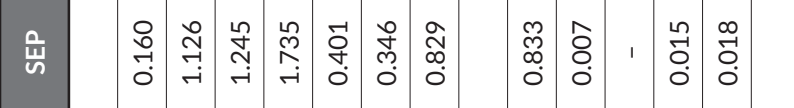

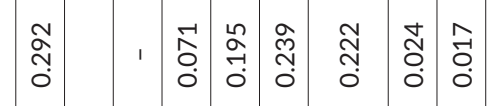

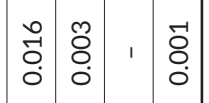

愛

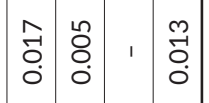

$\stackrel{+\frac{0}{3}}{3}$

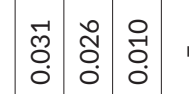

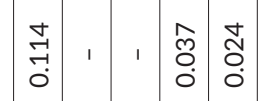

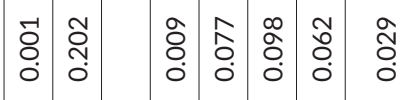

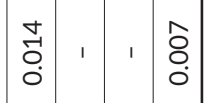

$\stackrel{\square}{\dddot{\Perp}}$

產

$+$

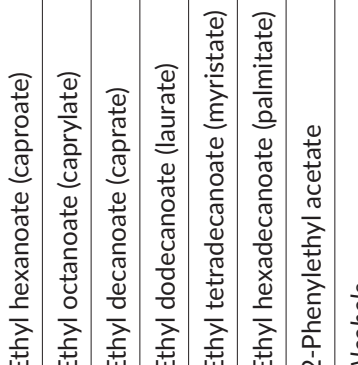

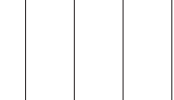

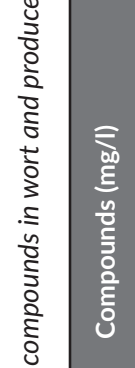

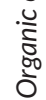

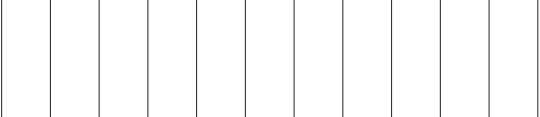

赔

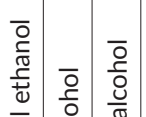

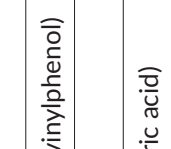

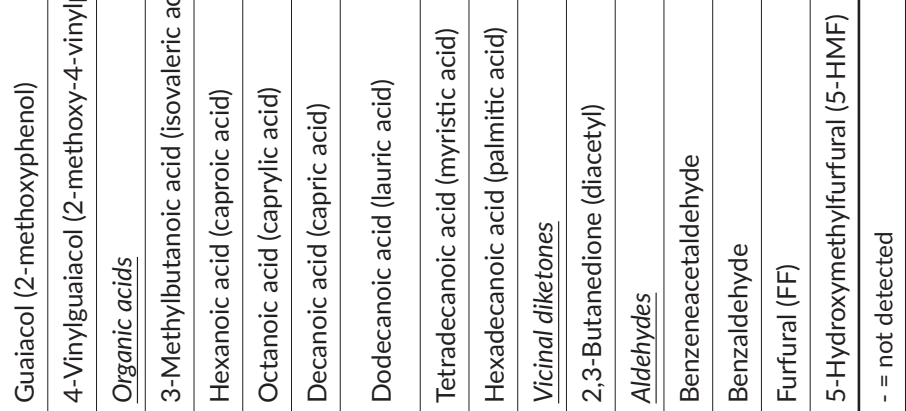


Brányik, T., Silva, D. P., Baszczynski, M., Lehnert, R., Almeida e Silva, J. B. (2012). A review of methods of low alcohol and alcohol-free beer production. Journal of Food Engineering, 108(4), 493-506. https:// doi.org/10.1016/j.jfoodeng.2011.09.020

Briggs, D. E., Boulton, C. A., Brookes P. A., Stevens, R. (2004). Brewing Science and Practice. Woodhead Publishing Limited and CRC Press LLC, 1-881. ISBN 978-1-85573-490-6

Buiatti, S. (2009). Beer Composition: An Overview. In: Beer in Health and Disease Prevention, (ed. Preedy, R. V.), Academic Press, 213-225. https://doi.org/10.1016/B978-0-12-373891-2.00020-1

Canonico, L., Agarbati, A., Comitini, F., Ciani, M. (2016). Torulaspora delbrueckii in the brewing process: A new approach to enhance bioflavour and to reduce ethanol content. Food Microbiology, 56(6), 45-51. https://doi.org/10.1016/j.fm.2015.12.005

Catarino, M., Mendes, A. (2011). Non-alcoholic beer - A new industrial process. Separation and Purification Technology, 79(3), 342-351. https://doi.org/10.1016/j.seppur.2011.03.020

Clapperton, F. J., Brown, W. G. D. (1978). Caprylic Flavour as a Feature of Beer Flavour. Journal of The Institute of Brewing, 84(2), 90-92. https://doi.org/10.1002/j.2050-0416.1978.tb03844.x

Contreras-Calderón, J., Guerra-Hernández, E., García-Villanova, B. (2008). Indicators of non-enzymatic browning in the evaluation of heat damage of ingredient proteins used in manufactured infant formulas. European Food Research and Technology, 227, 117-124. https://doi. org/10.1007/s00217-007-0700-2

De Francesco, G., Sannino, C., Sileoni, V., Marconi, O., Filippucci, S., Tasselli, G., Turchetti, B. (2018). Mrakia gelida in brewing process: An innovative production of low alcohol beer using a psychrophilic yeast strain. Journal of Food Microbiology, 76, 354-362. https://doi. org/10.1016/j.fm.2018.06.018

De Francesco, G., Turchetti, B., Sileoni, V., Marconi, O., Perretti, G. (2015). Screening of new strains of Saccharomycodes ludwigii and Zygosaccharomyces rouxii to produce low-alcohol beer. Journal of The Institute of Brewing and Distilling, 121(9), 113-121. https://doi. org/10.1002/jib.185

Domizio, P., House, F. J., Joseph, L. M. C., Bisson, F. L., Bamforth, W. C. (2016). Lachancea thermotolerans as an alternative yeast for the production of beer. Journal of The Institute of Brewing, 122(4), 599604. https://doi.org/10.1002/jib.362

Furdíková, K., Machyňáková, A., Drtilová, T., Špánik, I. (2020). Comparison of Different Categories of Slovak Tokaj Wines in Terms of Profiles of Volatile Organic Compounds. Molecules, 25(3), 669. https://doi. org/10.3390/molecules25030669

Gernat, D., Brouwer, E., Ottens, M. (2019). Aldehydes as Wort Off-Flavours in Alcohol-Free Beers - Origin and Control. Food and Bioprocess Technology, 13, 195-216. https://doi.org/10.1007/s11947-019-02374-z

Huerta-Zurita, R., Horsley, D. R., Schwarz, B. P. (2018). Is the Apparent Degree of Fermentation a Reliable Estimator of Fermentability. Journal of the American Society of Brewing Chemists, 77(1), 1-9. https:// doi.org/10.1080/03610470.2018.1553459

Ivanov, K., Petelkov, I., Shopska, V., Denkova, R., Gochev, V., Kostov, G. (2016). Investigation of mashing regimes for low-alcohol beer production. Journal of The Institute of Brewing, 122(3), 508-516. https://doi.org/10.1002/jib.351

Jiang, Z., Yang, B., Liu, X., Zhang, S., Shan, J., Liu, J. Wang, X. (2017). A novel approach for the production of a non-alcohol beer $(\leq 0.5 \% \mathrm{abv})$ by a combination of limited fermentation and vacuum distillation. Journal of The Institute of Brewing, 123(4), 533-536. https://doi.org/10.1002/jib.465

Kobayashi, M., Shimizu, H., Shioya, S. (2008). Beer volatile compounds and their application to low-malt beer fermentation. Journal of Bioscience and Bioengineering, 106(4), 317-323. https://doi. org/10.1263/jbb.106.317
Kochláňová, T., Kij, D., Kopecká, J., Kubizniaková, P., Matoulková, D. (2016a). Non-Saccharomyces Yeasts and Their Importance in the Brewing Industry. Part I -Brettanomyces (Dekkera). Kvasny prumysl, 62(7-8), 198-205. https://doi.org/10.18832/kp2016024

Kochláňová, T., Kij, D., Kopecká, J., Kubizniaková, P., Matoulková, D. (2016b). Non-Saccharomyces yeasts and their importance in the brewing industry. Part II. Kvasny prumysl, 62(7-8), 206-214. https://doi.org/10.18832/kp2016025

Krogerus, K., Gibson, B. R. (2013). Influence of valine and other amino acids on total diacetyl and 2,3-pentanedione levels during fermentation of brewer's wort. Applied Microbiology and Biotechnology, 97, 6919-6930. https://doi.org/10.1007/s00253-013-4955-1

Kurtzman, P. C., Fell, W. J., Boekhout, T., Robert, V. (2011). Chapter 7 Methods for Isolation, Phenotypic Characterization and Maintenance of Yeasts. In: The Yeasts (eds. Kurtzman, P. C., Fell, W. J., Boekhout, T.), Elsevier, 87-110. https://doi.org/10.1016/B978-0-444-521491.00007-0

Kyselová, L., Brányik, T. (2015). Quality improvement and fermentation control in beer. In: Advances in Fermented Foods and Beverages (ed. Holzapfel, W.), Woodhead Publishing, 477-500. https://doi. org/10.1016/B978-1-78242-015-6.00020-7

Landaud, S., Latrille, E., Corrieu, G. (2001). Top Pressure and Temperature Control the Fusel Alcohol/Ester Ratio through Yeast Growth in Beer Fermentation. Journal of The Institute of Brewing, 107(2), 107-117. https://doi.org/10.1002/j.2050-0416.2001.tb00083.x

Liguori, L., De Francesco, G., Russo, P., Perretti, G., Albanese, D., Di Matteo, M. (2015). Production and characterization of alcohol-free beer by membrane process. Food and Bioproducts Processing, 94(4), 158168. https://doi.org/10.1016/j.fbp.2015.03.003

Loira, I., Morata, A., Palomero, F., González, C., Suárez-Lepe A. J. (2018). Schizosaccharomyces pombe: A Promising Biotechnology for Modulating Wine Composition. Fermentation, 4(3), 70. https://doi. org/10.3390/fermentation4030070

McMurrough, I., Madigan, D., Donnelly, D., Hurley, J., Doyle, A. M., Hennigan, G., McNulty, N., Smyth, R. M. (1996). Control Of Ferulic Acid And 4-Vinyl Guaiacol In Brewing. Journal of The Institute of Brewing, 102(5), 327-332. https://doi.org/10.1002/j.2050-0416.1996. tb00918.x

Michel, M., Meier-Dörnberg, T., Jacob, F., Schneiderbanger, H., Hutzler, M. (2020). Optimisation of yeast vitality measurement to better predict fermentation performance. Journal of The Institute of Brewing, 126(2), 161-167. https://doi.org/10.1002/jib.604

Michel, M., Meier-Dörnberg, T., Jacob, F., Methner, F. J., Wagner, R. S., Hutzler, M. (2016). Review: Pure non-Saccharomyces starter cultures for beer fermentation with a focus on secondary metabolites and practical applications. Journal of The Institute of Brewing, 122(11), 569-587. https://doi.org/10.1002/jib.381

Montanari, L., Marconi, O., Mayer, H., Fantozzi, P. (2009). Production of Alcohol-Free Beer. In: Beer in Health and Disease Prevention (ed. Preedy, R. V.), Academic Press, 61-75. https://doi.org/10.1016/ B978-0-12-373891-2.00006-7

Negrutã, O., Csutak, O., Stoica, I., Rusu, E., Vassu, T. (2010). Methylotrophic yeasts: diversity and methanol metabolism. Romanian Biotechnological Letters, 15(4), 5369-5375. https://www.researchgate.net/ publication/266016918_Methylotrophic_yeasts_Diversity_and_ methanol_metabolism

NIST WebBook Chemie Database [online]. https://webbook.nist.gov/ chemistry/ [2020-8-24]

Olšovská, J., Vrzal, T., Štěrba, K., Slabý, M., Kubizniaková, P., Čejka, P. (2018). The chemical profiling of fatty acids during the brewing process. Journal of the Science of Food and Agriculture, 99(4), 1772-1779. https://doi.org/10.1002/jsfa.9369 
Olšovská, J., Čejka, P., Sigler, K. Hönigová, V. (2014). The Phenomenon of Czech Beer: a review. Czech Journal of Food Sciences, 32(4), 309319. https://doi.org/10.17221/455/2013-CJFS

Phiarais, P. N. B., Mauch, A., Schehl, D. B., Zarnkow, M., Gastl, M., Herrmann, M., Zannini, E., Arendt, K. E. (2010). Processing of a Top Fermented Beer Brewed from 100\% Buckwheat Malt with Sensory and Analytical Characterisation. Journal of The Institute of Brewing, 116(3), 265-274. https://doi.org/10.1002/j.2050-0416.2010.tb00430.x

Porter, T. J., Divol, B., Setati, M. E. (2019). Lachancea yeast species: Origin, biochemical characteristics and oenological significance. Food Research International, 119(5), 378-389. https://doi.org/10.1016/j. foodres.2019.02.003

Riu-Aumatell, M., Miró, P., Serra-Cayuela, A., Buxaderas, S., López-Tamames, E. (2014). Assessment of the aroma profiles of low-alcohol beers using HS-SPME-GC-MS. Food Research International, 57(3), 196-202. https://doi.org/10.1016/j.foodres.2014.01.016

Saison, D., De Schutter, P. D., Uyttenhove, B., Delvaux, F., Delvaux, R. F. (2009). Contribution of staling compounds to the aged flavour of lager beer by studying their flavour thresholds. Food Chemistry, 114(4), 1206-1215. https://doi.org/10.1016/j.foodchem.2008.10.078

Senkarcinova, B., Dias, I. A. G., Nešpor, J., Brányik, T. (2019). Probiotic alcohol-free beer made with Saccharomyces cerevisiae var. boulardii. LWT-Food Science and Technology, 100(10), 362-367. https://doi. org/10.1016/j.lwt.2018.10.082

Soares da Costa, M., Gonçalves, C., Ferreira, A., Ibsen, C., Guedes de Pinho, P., Silva Ferreira, A.C. (2004). Further Insights into the Role of Methional and Phenylacetaldehyde in Lager Beer Flavour Stability. Journal of Agricultural and Food Chemistry, 52(26), 7911-7917. https:// doi.org/10.1021/jf049178
Šavel, J., Košin, P., Brož, A. (2008). Colour changes during beer aging. Kvasny Prumysl. 54(2), 30-37. https://doi.org/10.18832/ kp2008003

The Goodscents Company [online] http://www.thegoodscentscompany. com/ [2020-8-24]

van der Walt. J.P. (1970). Genus Saccharomyces. In The Yeasts: A Taxonomic Study (1. Ladder. Ed.). pp.555-718. North Holland Publishing Company. Amsterdam.

Varela, J., Varela, C. (2019). Microbiological strategies to produce beer and wine with reduced ethanol concentration. Current Opinion in Biotechnology, 56(4), 88-96. https://doi.org/10.1016/j.copbio.2018.10.003

Viejo, G. C., Fuentes, S., Torrico, D. D., Godbole, A., Dunshea, R. F. (2019). Chemical characterization of aromas in beer and their effect on consumers liking. Food Chemistry, 293, 479-485. https://doi. org/10.1016/j.foodchem.2019.04.114

Villarreal-Soto, A. S., Beaufort, S., Bouajila, J., Souchard, P. J., Taillandier, P. (2018). Understanding Kombucha Tea Fermentation: A Review. Journal of Food Science, 83(3), 580-588. https://doi.org/10.1111/17503841.14068 